BMJ Open

Ophthalmology

\title{
Progression to severe visual impairment and blindness in POAG patients: pace and risk factors-a cohort study using German health claims data
}

\author{
Sophia Nestler (D , ${ }^{1}$ Daniel Kreft, ${ }^{1,2}$ Gabriele Doblhammer, ${ }^{1,2}$ Rudolf F Guthoff, ${ }^{3}$ \\ Stefanie Frech ${ }^{3}$
}

To cite: Nestler S, Kreft D, Doblhammer G, et al. Progression to severe visual impairment and blindness in POAG patients: pace and risk factors-a cohort study using German health claims data. BMJ Open Ophthalmology 2022;7:e000838. doi:10.1136/ bmjophth-2021-000838

Received 24 June 2021 Accepted 14 December 2021

\section{Check for updates}

(c) Author(s) (or their employer(s)) 2022. Re-use permitted under CC BY-NC. No commercial re-use. See rights and permissions. Published by BMJ.

${ }^{1}$ Institute for Sociology and Demography, University of Rostock, Rostock, Germany ${ }^{2}$ German Centre for Neurodegenerative Diseases, Bonn, Germany ${ }^{3}$ Department of Ophthalmology, Rostock University Medical Center, Rostock, Germany

Correspondence to Dr Daniel Kreft; daniel.kreft@ uni-rostock.de

\section{ABSTRACT}

Objective Glaucoma is a leading cause of severe visual impairment and blindness (SVI/B) worldwide. Hence, it is of utmost importance to explore relevant risk factors and study the pace of progression to SVI/B.

Methods and analysis We used a random sample of 250000 persons from administrative individual-level health records of the Allgemeine Ortskrankenkassen between 2004 and 2015. We identified 3535 primary open-angle glaucoma (POAG) patients aged 55 and older and followed them for up to 10 years. Monocular and binocular SVI/B were defined by the ICD-10 classifications $\mathrm{H} 54.0$ and H54.4. Ophthalmological and chronic disease risk factors were analysed by applying a multivariable Cox proportional hazard model.

Results The risk of SVI/B in POAG patients was significantly increased by the presence of specific additional eye diseases such as secondary glaucoma (HR: $3.08, p<0.001$ ), retinal vascular occlusion (HR: 3.00 , $\mathrm{p}<0.001)$ or age-related macular degeneration (AMD) (HR: $2.26, p<0.001)$. The risk was highest in the first 2 years after the POAG diagnosis and significantly decreased after the fifth year (HR: 0.36, $p=0.002$ ). Ocular injuries, other ocular diseases, non-ophthalmological comorbidities, and age and sex had no significant influence ( $p>0.05$ ).

Conclusion Although progression to $\mathrm{SVI} / \mathrm{B}$ is relatively rare in POAG patients in Germany, one must be aware of additional risk factors, such as secondary glaucoma, retinal vascular occlusion and AMD. Regular ophthalmological examinations help prevent the progression of SVI/B, especially in the first years after the POAG diagnosis. Specific, targeted, and timely treatments for the other eye diseases could help prevent or delay SVI/B.

\section{BACKGROUND}

Glaucoma is one of the leading causes of blindness worldwide. Primary open-angle glaucoma (POAG) is the most common type, accounting for $74 \%$ (58.9 million) of all glaucoma cases in $2020 .{ }^{1}$ For the same year, Kapetanakis et al estimated that 65.5 million people worldwide, as well as $2.1 \%$ of the European population aged $40+$ years, suffered from POAG. ${ }^{2}$ Concerning visual impairment, the number of people of all ages is estimated

\section{Key messages}

What is already known about this subject?

- Glaucoma is one of the leading causes of irreversible blindness worldwide with primary open-angle glaucoma being the predominant subtype accounting for $74 \%$ of all glaucoma cases in 2020 .

\section{What are the new findings?}

A number of risk factors in primary open-angle glaucoma (POAG) patients, which increase the risk of severe visual impairment and blindness (SV/B), were identified, such as additional eye diseases and disease duration.

How might these results change the focus of research or clinical practice?

To know about risk factors and incident eye diseases of POAG patients might help to prevent the progression of SVI/B, especially in the first years after diagnosis. Adequate disease management is of immense importance to assess the need for medical care interventions and to further improve medical care.

to be 285 million, while those aged 50 years and older represent $65 \%$ of the visually impaired. $^{3}$

POAG is not only one of the most common eye diseases worldwide, but also one of the major causes of blindness in Germany. ${ }^{45}$ In addition to age-related macular degeneration (AMD) and diabetic retinopathy, POAG continues to represent the second leading risk factor for becoming blind in Germany and in Western Europe. ${ }^{67}$ In 2006, glaucoma caused $15.4 \%$ of all cases of blindness in the German population. ${ }^{8}$ Despite a slight decrease in the incidence of vision loss in developed countries over the past decades, there is ample evidence of cataracts and diabetic retinopathy to still substantially increase its risk. ${ }^{49}$

After a diagnosis of POAG, the aim is to slow or to prevent any further progression of the disease by lowering the intraocular 
pressure (IOP). New IOP-lowering therapies, as well as new diagnostic and progression analysis methods, are continually developing and being improved..$^{10}$ These enhancements in glaucoma treatment have helped many patients; nevertheless, lifelong regular follow-up examinations are necessary to ensure their effectiveness. The impact of POAG on the rate of severe visual impairment and blindness (SVI/B) in the general population is poorly understood, as POAG often shows no symptoms until advanced stages. ${ }^{11}$ Due to the interaction of various risk factors, POAG patients still suffer from progression of visual function loss, which implies the need to provide further evidence on this topic.

An advantage of studies focusing on the incidence of eye diseases concerns the potential to identify relevant risk factors which affect future visual outcomes. For the pathogenesis of SVI/B, relevant conditions include AMD, retinopathy, glaucoma and cataract as well as myopia, retinal vascular occlusions, injuries of the eye and optic nerve diseases. ${ }^{5812-16}$ Based on the results of our previous study, which referred to the impact of incident eye diseases on the risk of SVI/B, in this study we analysed ten eye diseases as risk factors for the incidence of SVI/B in incident POAG patients. ${ }^{17}$

The epidemiology of SVI/B is also closely linked to demographic changes. Because the proportion of the elderly population will increase, there will be a further increase in both the prevalence of age-related eye diseases as well as in the proportion of individuals with SVI/B by $2030 .{ }^{5718}$

As POAG patients often have comorbid eye diseases, one hypothesis was that these additional eye diseases lead to a significant increase of the risk of SVI/B, although it is unclear which of these might pose the greatest risk factor when considered simultaneously. Therefore, our outcome measure included not only the transition to blindness but also to severe visual impairment. The second hypothesis dealt with the risk of SVI/B, which may be highest in the first few years after diagnosis, due to the fact that patients only consult an ophthalmologist when they first start to notice vision loss, even though the glaucoma is often at an advanced stage.

In Germany, severe visual impairment is defined by a visual acuity of $1 / 20$ and less, regulated at the state level by the State Blindness Benefit Law. According to German law, legal blindness is a reduction of visual acuity to $1 / 50$ (0.02). According to the WHO and the international classification system, blindness is defined by the threshold of visual acuity of $1 / 20(0.05)$, which, according to ICD-10 coding, also includes severe visual impairment. This study uses the ICD-10 coding system as a basis, which combines $\mathrm{SVI} / \mathrm{B}$ in one coding number.

Hence, the first aim of our study was to analyse the risk of severe monolateral or bilateral SVI/B in incident POAG patients. Second, we examined the pace of progression to SVI/B from the onset of POAG. Our third aim concerned the analysis of comorbid eye diseases as risk factors for SVI/B controlling for multimorbidity.

\section{DATA AND METHODS}

\section{Data source}

Data analysis is based on a random sample selection of 250000 patients drawn from Germany's largest public health insurance company-the Allgemeine Ortskrankenkassen (AOK). The scientific institute of the AOK (WIdO) granted access to these data. The dataset included both persons from private households and from nursing homes. An observation period between 2004 and 2015 allowed for a 12-year follow-up of patient information on a quarterly basis. A change of the health insurance or death led to withdrawal from the sample. The routine data covered basic demographic characteristics such as sex, date of birth and death, as well as confirmed inpatient and outpatient diagnoses coded by the International Statistical Classification of Diseases and Related Health Problems (ICD-10-GM). It was not appropriate or possible to involve patients or the public in the design, conduct, reporting or dissemination plans of our research.

\section{Definition of SVI/B, POAG, and risk factors of SVI/B}

We coded the outcome SVI/B using ICD H54.4 and H54.0. No information about the leading causes of SVI/B was available. Our main exposure variable POAG is based on ICD H40.1.

All patients with an incident POAG diagnosis (ICD: H40.1) were analysed. We defined the following selected eye diseases as risk factors: primary angle-closure glaucoma (ICD: H40.2), secondary glaucoma (ICD: H40.3-H40.6), myopia (ICD: H44.2, H52.1, H52.5), injuries of the eye (ICD: S05, T15, T26), AMD (ICD: H35.3), retinopathy (ICD: H35.0-H35.2) including diabetic retinopathy (ICD: H36.0), cataracts (ICD: H25-H26) including diabetic cataracts (ICD: H28.0), retinal vascular occlusion (ICD: H34) and disorders of optic nerves (ICD: H46-H48). As an independent risk factor of SVI/B, we considered type 2 diabetes mellitus (ICD: E11). In addition, we explored the effect of disease-duration of POAG by categorising patients into groups of 1 st year, 2nd year, 3rd to 5th year and 6 th to 10 th year since their first valid diagnosis.

\section{Control variables}

The demographic control variables were age at the first POAG-diagnosis (55-59, 60-64, 65-69, 70-74, 75-79, $80-84,85-89,90+)$, as well as sex. For analysis, the multimorbidity status of patients was categorised into none, $1-2,3-4$ or 5 or more severe comorbidities and consisted of the following non-ophthalmic diagnoses: acute myocardial infarction (ICD: I21-I22, I25.2), cerebrovascular diseases (ICD: G45-G46, H34.0, I6), ischaemic (ICD: I20-I25) and other heart diseases (ICD: I43, I50, I09.9, I11.0, I13.0-2, I25.5, I42.0-9, P29.0), cancer (ICD: C00C97), kidney (ICD: N11-N19, I12.0, I13.1-2, N03.2-7, N05.2-7, N25-N29, Z49.0-2, Z94.0, Z99.2), liver (ICD: B18, K70, K71.1,3,4,5,7, K72.1,9, K76.0,2-9, Z94.4) and lung diseases (ICD: J44), nervous diseases (ICD: G0-1, G4-9, G20-22, G23.0,2,8,9, G24-26, G31.2,9, G31.81,88, 
G32,35-37), dementia (ICD: F00.0-9, F01.0-9, F02.0-8, F03, F05.1, G23.1, G30.0-9, G31.0 G31.82) and injuries of hips and legs (ICD: S7-S9).

\section{Validation strategy of the eye diseases}

As an internal validation strategy, all selected eye diseases matched the M2Q-criterion (minimum two quarters criterion) to reduce the problem of false-positive diagnoses. ${ }^{19}$ To ensure the validity of a first diagnosis, a second diagnosis in another quarter during the observation period was necessary. All covariates, with the exception of sex and age at incident POAG-diagnosis, were considered to be time-varying variables with the value of ' 1 ' since first valid diagnosis and ' 0 ' otherwise.

\section{Sample selection procedure}

The data set comprised 249742 persons in the first quarter of 2004, with plausible information on the date of birth and death. We excluded 230896 persons who had no valid POAG-diagnosis throughout the entire observation period. To explore the pace of the transition to SVI/B for incident POAG patients, we defined the 2 years 2004 and 2005 as wash-out periods, and excluded all patients who had a diagnosis of POAG $(n=344)$ or SVI/B $(n=30)$ in these 2 years. To assure that the duration of POAG was not confounded by the duration of the other eye diseases, we also excluded patients who had at least one of the listed eye diseases during the wash-out period $(n=11990)$. We studied the incidence of POAG from the first quarter of 2006 onwards. An additional 2862 patients were dropped due to death or change of health insurance. Another 85 persons with a simultaneous diagnosis of POAG and $\mathrm{SVI} / \mathrm{B}$ were excluded, as well as patients under the age of 55 years at the time of the valid glaucoma-diagnosis. The final study sample consisted of 3535 patients with

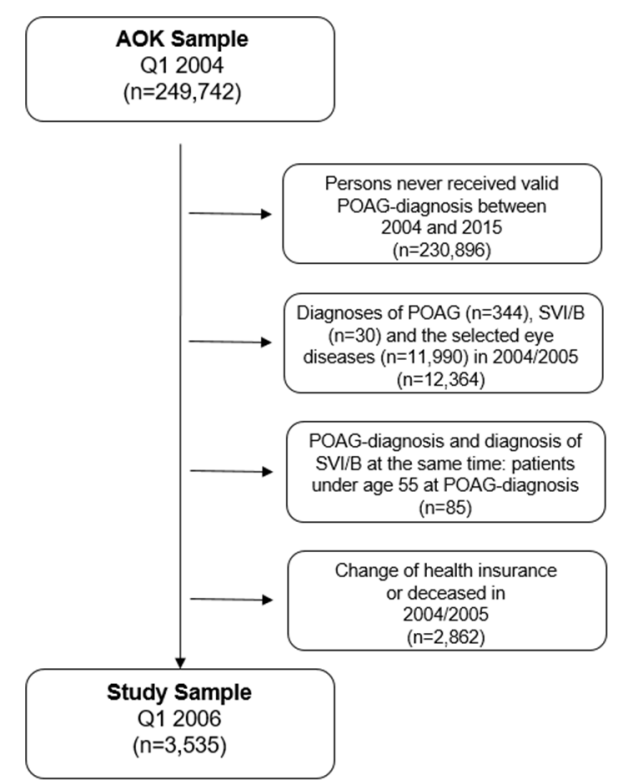

Figure 1 Flowchart of sample selection procedure. AOK, Allgemeine Ortskrankenkassen; POAG, primary open-angle glaucoma; SVI/B, severe visual impairment and blindness.

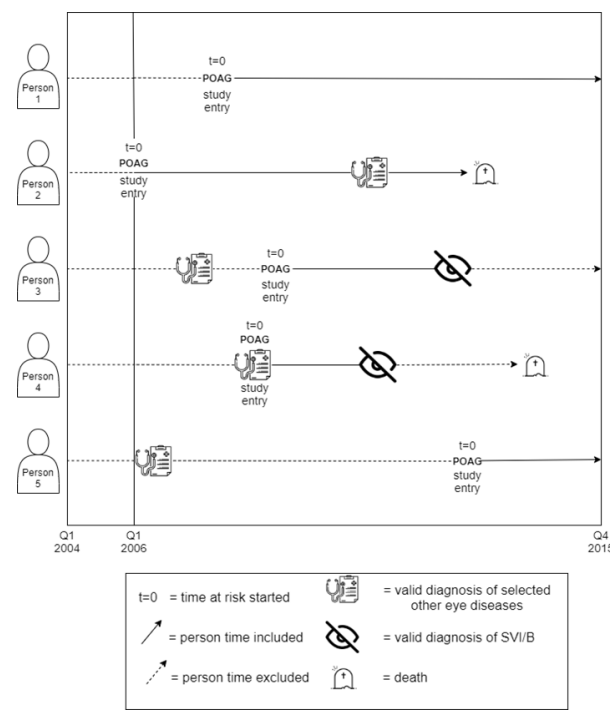

Figure 2 Time at risk in multivariable analysis. POAG, primary open-angle glaucoma; SVI/B, severe visual impairment and blindness.

incident POAG diagnosed between 2006 and 2015 with a maximum follow-up of 10 years (figure 1 ).

\section{Analysis strategy and statistical methods}

Parametric proportional-hazards models were performed including sex, age, selected eye diseases which are associated with an elevated risk of SVI/B, multimorbidity and the duration since the onset of POAG. Analysis time was measured in quarters and started at the first valid POAGdiagnosis and ended with death or change of health insurance (figure 2, person 1), valid diagnosis of SVI/B (figure 2, persons 3 and 4), or due to right censoring in Q4 2015 (figure 2, persons 1 and 5). The censoring time was set to the middle of the last observed quarter of SVI/B-diagnosis and for deaths in the month of death. We assumed analysis time to follow an exponential distribution with a constant baseline hazard over time. All statistical analysis was performed using Stata (V.16.1).

\section{RESULTS}

\section{Characteristics of study population}

The final study population comprised 3535 incident POAG patients of whom 109 received an additional diagnosis of SVI/B between 2006 and 2015 (table 1). The number of POAG and SVI/B patients increased with age: the majority received their first diagnosis of POAG at the ages of 70 to $74(\mathrm{n}=762,21.56 \%)$ and 75 to $79(\mathrm{n}=784$, $22.18 \%)$, while $25.69 \%(\mathrm{n}=28)$ suffered from SVI/B between 80 and 84 years. Approximately two-thirds of POAG patients were female $(n=2265,64.07 \%)$, which was also true for SVI/B $(n=74,67.89 \%$ females vs $n=35$, $32.11 \%$ males).

At study entry, $84.64 \%$ ( $n=2992)$ of all patients suffered from cataract, about one-third from disorders of optic nerve $(n=1171,33.13 \%)$, retinopathy $(n=1142,32.31 \%)$ or myopia $(\mathrm{n}=1122,31.74 \%) .28 .29 \%(\mathrm{n}=1000)$ of POAG patients showed AMD, and angle-closure glaucoma 
Table 1 Descriptive overview of patients' characteristics at the time of SVI/B and study entry, 2006-2015

\section{Covariates}

\section{At time of SVI/B 2006-2015}

At time of study entry 2006-2015

Age at POAG-diagnosis

\begin{tabular}{ll}
\hline $55-59$ & \\
\hline $60-64$ & 1 \\
$65-69$ & 17 \\
$70-74$ & 25 \\
$75-79$ & 28 \\
$80-84$ & 18 \\
$85-89$ & \\
$90+$ & \\
Sex &
\end{tabular}

Male 35

Female

35

74

3

4

12

17

25

28

18

2

Eye diseases (ever diagnosed after 2005)

\section{Cataract}

\begin{tabular}{|c|c|c|c|c|}
\hline No & 6 & $5.50 \%$ & 543 & $15.36 \%$ \\
\hline Yes & 103 & $94.50 \%$ & 2992 & $84.64 \%$ \\
\hline \multicolumn{5}{|c|}{ Age-related macular degeneration } \\
\hline No & 46 & $42.20 \%$ & 2535 & $71.71 \%$ \\
\hline Yes & 63 & $57.80 \%$ & 1000 & $28.29 \%$ \\
\hline \multicolumn{5}{|c|}{ Disorders of optic nerve } \\
\hline No & 56 & $51.38 \%$ & 2364 & $66.87 \%$ \\
\hline Yes & 53 & $48.62 \%$ & 1171 & $33.13 \%$ \\
\hline \multicolumn{5}{|l|}{ Myopia } \\
\hline No & 66 & $60.55 \%$ & 2413 & $68.26 \%$ \\
\hline Yes & 43 & $39.45 \%$ & 1122 & $31.74 \%$ \\
\hline \multicolumn{5}{|c|}{ Retinopathy } \\
\hline No & 67 & $61.47 \%$ & 2393 & $67.69 \%$ \\
\hline Yes & 42 & $38.53 \%$ & 1142 & $32.31 \%$ \\
\hline \multicolumn{5}{|c|}{ Secondary glaucoma } \\
\hline No & 88 & $80.73 \%$ & 3347 & $94.68 \%$ \\
\hline Yes & 21 & $19.27 \%$ & 188 & $5.32 \%$ \\
\hline \multicolumn{5}{|c|}{ Retinal vascular occlusions } \\
\hline No & 88 & $80.73 \%$ & 3371 & $95.36 \%$ \\
\hline Yes & 21 & $19.27 \%$ & 164 & $4.64 \%$ \\
\hline \multicolumn{5}{|c|}{ Angle-closure glaucoma } \\
\hline No & 92 & $84.40 \%$ & 3301 & $93.38 \%$ \\
\hline Yes & 17 & $15.60 \%$ & 234 & $6.62 \%$ \\
\hline \multicolumn{5}{|c|}{ Injuries of the eye } \\
\hline No & 104 & $95.41 \%$ & 3440 & $97.31 \%$ \\
\hline Yes & 5 & $4.59 \%$ & 95 & $2.69 \%$ \\
\hline \multicolumn{5}{|c|}{ Ever diagnosed type 2 diabetes mellitus } \\
\hline No & 63 & $57.80 \%$ & 2047 & $57.91 \%$ \\
\hline Yes & 46 & $42.20 \%$ & 1488 & $42.09 \%$ \\
\hline \multicolumn{5}{|c|}{ Comorbidities } \\
\hline None & 3 & $2.75 \%$ & 347 & $9.82 \%$ \\
\hline
\end{tabular}




\begin{tabular}{|c|c|c|c|c|}
\hline \multirow{2}{*}{$\begin{array}{c}\text { Covariates } \\
1-2\end{array}$} & \multicolumn{2}{|c|}{ At time of SVI/B 2006-2015 } & \multicolumn{2}{|c|}{ At time of study entry $2006-2015$} \\
\hline & 26 & $23.85 \%$ & 1341 & $37.93 \%$ \\
\hline $3-4$ & 35 & $32.11 \%$ & 1020 & $28.85 \%$ \\
\hline $5+$ & 45 & $41.28 \%$ & 827 & $23.39 \%$ \\
\hline \multicolumn{5}{|c|}{ Year since POAG diagnosis } \\
\hline 1st year & 22 & $20.18 \%$ & 3535 & $100.00 \%$ \\
\hline 2nd year & 26 & $23.85 \%$ & 0 & $0.00 \%$ \\
\hline 3rd-5th year & 46 & $42.20 \%$ & 0 & $0.00 \%$ \\
\hline 6 th-10th year & 15 & $13.76 \%$ & 0 & $0.00 \%$ \\
\hline Total & 109 & $100 \%$ & 3535 & $100 \%$ \\
\hline
\end{tabular}

POAG, primary open-angle glaucoma; SVI/B, severe visual impairment and blindness.

affected $6.62 \%(\mathrm{n}=234) .5 .32 \% \quad(\mathrm{n}=188)$ of persons had an additional diagnosis of secondary glaucoma. The proportion of patients with retinal vascular occlusions amounted to $4.64 \% \quad(n=164)$, whereas injuries of the eye concerned a minority of the sample $(n=95,2.69 \%)$.

Compared with study entry, at the time of SVI/B the prevalence of eye diseases had increased for AMD $(n=63$, $57.80 \%)$, retinal vascular occlusions $(\mathrm{n}=21,19.27 \%)$, secondary glaucoma $(\mathrm{n}=21,19.27 \%)$ and angle-closure glaucoma $(n=17,15.60 \%)$. A large majority of patients suffered from cataract $(n=103,94.50 \%)$, whereas the prevalence of injuries of the eye $(n=5,4.59 \%)$, myopia $(\mathrm{n}=43,39.45 \%)$, retinopathy $(\mathrm{n}=42,38.53 \%)$ and disorders of optic nerve $(n=53,40.37 \%)$ was marginally higher at the time of SVI/B than at first POAG-diagnosis.

At study entry, $42.09 \% \quad(n=1488)$ suffered from type 2 diabetes mellitus which also affected $42.20 \%(n=46)$ of patients at the time of SVI/B. At the time of SVI/B, $2.75 \%$ $(n=3)$ of the patients did not have any severe comorbidities but $41.28 \%(\mathrm{n}=45)$ had five or more comorbid diagnoses. Conversely, at study-entry, the number of comorbidities decreased from two onwards. In $42.20 \%$ $(\mathrm{n}=46) \mathrm{SVI} / \mathrm{B}$ occurred between 3 and 5 years after the first POAG-diagnosis, decreasing to $13.76 \%(\mathrm{n}=15)$ after 6-10 years from POAG diagnosis.

\section{Multivariable regression analysis of risk factors}

POAG patients with angle-closure glaucoma, AMD, retinal vascular occlusions and secondary glaucoma had a two to three times significantly higher risk of SVI/B compared with persons without these eye diseases (table 2). In detail, the risk of SVI/B was the highest for secondary glaucoma (HR: $3.08,95 \%$ CI 1.89 to $5.02, \mathrm{p}<0.001$ ) and retinal vascular occlusions (HR: $3.00,95 \%$ CI 1.83 to $4.90, \mathrm{p}<0.001$ ), followed by angle-closure glaucoma (HR: 1.98, 95\% CI 1.17 to 3.35, $\mathrm{p}=0.011$ ) and AMD (HR: 2.26, $95 \%$ CI 1.52 to $2.37, \mathrm{p}<0.001)$. Patients with injuries of the eye, myopia, retinopathy, cataract or disorders of optic nerve also showed an enhanced risk of SVI/B, but this was not confirmed by the conventional significance levels $(\mathrm{p}<0.05)$.
Diabetes mellitus type 2 did not affect the risk of SVI/B (HR: $0.81,95 \%$ CI 0.63 to $1.04, \mathrm{p}=0.100$ ). With an increasing number of non-ophthalmic comorbidities, the risk increased nearly twofold, but not significantly. A longer disease duration up to 10 years of POAG was associated with a lower risk of SVI/B. Compared with patients in the second year since the onset of POAG, persons with a valid POAG-diagnosis from 6 years and more had a $64 \%$ (HR: $0.36,95 \%$ CI 0.19 to $0.68, p=0.002$ ) lower risk of SVI/B. No significant differences existed up to 5 years. Age and sex of POAG patients had no significant effect on the risk of SVI/B.

\section{DISCUSSION}

\section{Glaucoma incidence and SVI/B}

POAG is one of the major eye diseases in Germany and also a leading cause of blindness worldwide. ${ }^{1}$ Our study revealed a low risk of SVI/B among POAG patients, as 109 of 3535 POAG patients (3\%) suffered from monocular or binocular SVI/B within 10 years of the onset of POAG. Previous studies have already demonstrated that patients who received their first POAG diagnosis after 1980 had a decreased risk of SVI/B, which is attributable to the development of appropriate medical treatment as well as optimal surgical strategies. ${ }^{10}{ }^{20}$ The risk of experiencing SVI/B in our study was concentrated in the first years after the POAG-diagnosis and became significantly lower after 6-10 years compared with disease onset. In the study of Yonekawa and colleagues, $1.2 \%$ of participants developed incident visual impairment, $2.9 \%$ developed monocular VI with a 4-year incidence and $1.2 \%$ developed monocular blindness. ${ }^{21}$ These numbers are similar to those we found, where $3 \%$ of patients developed incident SVI/B, with the difference that we also included patients developing incident binocular blindness. In our study, we not only benefitted from the long-term follow-up and the number of patients included, but also from information about the time at which POAG-patients received incident diagnoses of additional eye diseases. Thus, our study is better suited to differentiate between the effect of POAG and the effects of other eye diseases on the transition 
Table 2 Results of multivariable regression model, 2006-2015

\section{Covariates}

Cataract

No

Yes

Age-related macular degeneration

No

Yes

Disorders of optic nerve

No

Yes

Myopia

No

Yes

Eye diseases (ever diagnosed after 2005)

Retinopathy

No

Yes

1.02

Secondary glaucoma

No

Yes

Retinal vascular occlusions

$\begin{array}{ll}\text { No } & 1.00 \\ \text { Yes } & 3.00\end{array}$

Angle-closure glaucoma

No

Yes

Injuries of the eye

$\begin{array}{ll}\text { No } & 1.00 \\ \text { Yes } & 1.37\end{array}$

Ever type 2 diabetes mellitus

$\begin{array}{ll}\text { No } & 1.00 \\ \text { Yes } & 0.81 \\ \text { Comorbidities } & \end{array}$

None

3-4

$5+$

1.00

1.70

2.32

2.57

Year since POAG diagnosis

$\begin{array}{ll}\text { 1st year } & 0.93 \\ \text { 2nd year } & 1.0 \\ \text { 3rd-5th year } & 0.72 \\ \text { 6th-10th year } & 0.36\end{array}$

Age at POAG-diagnosis

\begin{tabular}{|c|c|c|c|}
\hline $55-59$ & 1.00 & & \\
\hline $60-64$ & 0.79 & 0.757 & (0.18 to 3.54 ) \\
\hline $65-69$ & 1.05 & 0.945 & (0.29 to 3.76$)$ \\
\hline
\end{tabular}




\begin{tabular}{clll}
\hline Table 2 Continued & & & \\
\hline Covariates & HR & P value & $\mathbf{9 5 \%} \mathbf{C l}$ \\
\hline $70-74$ & 0.80 & 0.731 & $(0.23$ to 2.81$)$ \\
$75-79$ & 1.03 & 0.962 & $(0.30$ to 3.54$)$ \\
$80-84$ & 1.30 & 0.676 & $(0.38$ to 4.49$)$ \\
$85-89$ & 1.79 & 0.372 & $(0.50$ to 6.39 \\
$90+$ & 0.68 & 0.679 & $(0.11$ to 4.26$)$ \\
Sex & & & \\
Males & 1.00 & 0.538 & $(0.75$ to 1.73$)$ \\
\hline Females & 1.14 & \\
\hline
\end{tabular}

POAG, primary open-angle glaucoma.

to SVI/B than earlier studies. Furthermore, the total number of $3 \%$ may be attributable to the German healthcare system, which entails a regular 3-month follow-up after the first glaucoma diagnosis. In addition, Germany has a Disease Management Programme (DMP), which aims to increase the cooperation between general practitioners and ophthalmologists, thereby improving the coordination of therapies after the onset of the disease. However, with the exclusion of prevalent eye diseases at study entry, our sample may represent a healthier selection of POAG patients, which may account for the lower number of persons with SVI/B. The health selection into the study group also concerned the age of the incident POAG patients, as the majority received their first diagnosis later in life (75-79 years). The number of $3 \%$ incident glaucoma patients seems to be low compared with other studies, where a late presentation was the main cause for $23 \%$ of patients eligible for blindness registration, reducing to $12 \%$ in a study conducted a decade later. ${ }^{22} 23$ These results still seem low compared with other studies, in which $30 \%-35 \%$ of the patients presented bilaterally blind to the clinic or were blind at the end of follow-up. ${ }^{24-26}$ In contrast to these high numbers, prevalence of bilateral blindness was $0.02 \%$ when combinations of glaucoma and other causes were included. $^{27}$

\section{Glaucoma pace and worsening of SVI/B}

The analysis of the pace showed that almost half of all individuals with SVI/B received their diagnosis between 3 and 5 years after POAG onset, whereas after 5 years since the first POAG diagnosis the risk for SVI/B decreased significantly. In context of the worsening of SVI/B, incident additional eye diseases with an onset prior to first POAG diagnosis need to be considered, while the contribution of the history of additional eye diseases as a risk factor for VI has been described earlier. Yonekawa and colleagues demonstrated that persons with a history of eye diseases are predisposed to develop vision loss either due to the presence of a progressive ocular or systemic condition or due to increased environmental exposure to factors that may contribute to progressive vision loss. ${ }^{21}$ Another study investigating the rate of change in patients with POAG showed a median time of worsening at 7.5 years, after which the progression slowed. Also, deterioration was higher among patients with more advanced glaucoma at the time of initial presentation. ${ }^{28}$ Several reasons may be responsible for progression within the first 5 years of POAG onset: delayed consultation of an ophthalmologist or, as described by Eid and colleagues, the progression of glaucoma was rapid. Another possibility concerned an ineffective therapy to lower IOP, which failed to attenuate the progression of the disease.

\section{Eye disease-related risk factors and SVI/B}

We identified several eye diseases as additional risk factors of SVI/B, such as secondary glaucoma and retinal vascular occlusions. We also confirmed additional adverse effects of AMD and angle-closure glaucoma. These eye diseases generally increase the risk of SVI/B, however, among POAG patients it is even more necessary to closely monitor whether these additional eye diseases develop. ${ }^{29}$ Ocular morbidities contributing to sight loss in addition to glaucoma have also been described by others. In the study of Kotecha et al 29 patients of 100 had a secondary comorbidity contributing to sight loss, with some of the same ocular diseases investigated in our study, such as retinal vascular occlusion, macular detachment including AMD, traumatic ocular injury and high myopia. Nevertheless, glaucoma was listed as the primary cause of visual impairment. ${ }^{11}$ As early as 1980 Luntz and Schenker confirmed the correlation between the incidence of glaucoma and retinal vascular occlusion. ${ }^{30}$ Chen evaluated patterns of blindness in POAG patients, whereby a significant risk factor for developing blindness over time was visual field loss at POAG diagnosis. ${ }^{20}$ Late detection and a higher IOP constituted significant risk factors in the study of Kooner and colleagues. ${ }^{31}$ Blomdahl and colleagues investigated risk factors for bilateral blindness and also the extent to which other eye diseases contributed in 210 patients, who represented $11 \%$ of the total cohort. Macular degeneration was the most common disease contributing to visual impairment in this group, with $52.9 \%$, followed by cataract with $17.1 \%$ and retinal vein occlusion with $10 \%$. In addition, some patients had more than one contributing eye disease, 
similar to our study. ${ }^{27}$ The authors concluded that blindness in glaucoma patients is primarily due to other eye diseases. Therefore, our study leads to the conclusion that comorbid other eye diseases represented one of the most significantly found risk factors for SVI/B in POAG patients.

\section{Sociodemographic-related risk factors (age and gender)}

In our study, POAG patients of different age groups as well as both sexes showed the same risk for SVI/B. Paula et al investigated possible risk factors for blindness and revealed similar results: age and gender were not associated with unilateral and bilateral blindness, with $24.5 \%$ of investigated POAG patients presented unilateral and $34.0 \%$ presented bilateral blindness from glaucoma. Paula and colleagues examined risk factors of blindness in patients with open-angle glaucoma within a follow-up time of at least 15 years and also showed that sex was not associated with an enhanced risk of blindness. ${ }^{26}$ The Reykjavik Eye Study, the Melbourne Visual Impairment Project and the Priverno Eye Study also demonstrated no sex-related differences, similar to our results. ${ }^{32-34}$ In agreement with Kwon et al, who evaluated the long-term visual field outcome in POAG, no differences in the risk of SVI/B in POAG patients among the sexes were detected. ${ }^{35}$ In Germany, gender-specific and age-specific differences can be found in the non-cause-specific incidence of blindness, but these do not apply to the risk of SVI/B among POAG patients. ${ }^{4}$ On the contrary, older age was a risk factor for incident VI, monocular VI and worsening vision in the Los Angeles Latino Eye Study (LALES) and for the progression of visual field loss of POAG patients. ${ }^{21} 3637$ Also, a number of populationbased studies investigating different ethnicities, within a follow-up period of 3-7 years and a sample size larger than 500, such as the Beaver Dam Study, the Blue Mountain Study, the Barbados Eye Study and others, identified older age as a risk factor for incident VI. ${ }^{32-34} 38-41$

\section{Non-eye disease-related risk factors and SVI/B}

In our SVI/B cohort, $23.8 \%$ of patients had 1-2 comorbidities, $32.1 \%$ had $3-4$ comorbidities and $41.2 \%$ had more than five comorbidities, other than eye diseases. Our descriptive analysis showed that a higher number of non-eye-related diseases increased the risk of SVI/B, however, this gradient was not significant in multivariable analysis. This number was very similar to the number $(41 \%)$ of patients who had two or more comorbidities in the LALES, which investigated risk factors for incident visual impairment and monocular blindness. ${ }^{21}$

Population-based studies showed that persons with diabetes are predisposed to developing multiple ophthalmic conditions, including diabetic retinopathy, cataract, optic nerve damages, as well as glaucoma and central vein occlusion. ${ }^{21} 29$ Although $42 \%$ of patients included in our study had diabetes mellitus type 2, it was not a risk factor for SVI/B. The absence of an increased risk for SVI/B in prevalent diabetic patients is attributable to our study design: because we controlled for the risk of SVI/B in incident additional eye diseases potentially caused by diabetes in our study, the effect of diabetes mellitus as such was absent. Furthermore, cataract surgery constitutes a routine intervention in developed countries and the risk for SVI/B decreased significantly, which is also true for POAG patients. ${ }^{43}$ Another major factor for diabetes not being identified as a risk factor might be Germany's DMP. This potentially increased utilisation of ophthalmic services, leading to a more frequent diagnosis of POAG of diabetic patients.

\section{Limitations and strengths}

By using health claims data we benefitted from a large sample size as well as from a high number of POAGdiagnoses confirmed by inpatient and outpatient ophthalmologists. We attained improvement of validity and minimised false-negative diagnosis by the use of 'M2Q-criterion'. The cohort study design offered a longterm follow-up of patients' health progression; however, false negative POAG-diagnoses due to right censoring were possible if patients received their second POAGdiagnosis after Q4 2015. Despite the adjustment of control variables in multivariable analysis, the data provided no information about cause-specific SVI/B. We investigated monocular and binocular SVI/B, which consisted of incident POAG patients as well as of patients with incident other eye diseases. Hence, the strict inclusion criteria may account for the small number of cases of SVI/B. One limitation to be aware of is the increasing selection bias due to mortality and change of health insurers with increasing duration of the observation period. Also, as the ICD-10 coding includes SVI/B, no conclusion about blindness itself and the reasons for blindness were possible from these data. However, it may also be seen as a strength of the study that it is not confined to blindness alone. An advantage of health claims data is the composition of the sample, including persons from both private households and nursing homes. There was no mortality selection into as well as out of the AOK sample. There is no bias due to survey sample-selection or non-response. The AOK covers almost one third of the German population but it covers roughly half of the population aged 70 and older. There is an insurance selection bias, implying a worse health profile of the insured compared with the average population. Thus, while our sample may not be representative of the total German population in terms of incidence and prevalence of diseases, the mechanisms leading to SVI/B certainly are.

Due to differences in age selection criteria, ethnicity, follow-up time, definitions of risk factor and end-points, Yonekawa and colleagues discuss the importance of general considerations of risk associations rather than directly compare studies. ${ }^{21}$ The authors address exactly these points we also consider to be of immense importance. In addition to the criteria mentioned above, there is the additional issue of different definitions of visual impairment, blindness and glaucoma in different regions 
of the world. These points should always be kept in mind when discussing results from different countries.

\section{CONCLUSION}

The risk of SVI/B of incident glaucoma patients in Germany is generally low. Our results revealed that if SVI/B develops, it occurs within 2years after the first glaucoma diagnosis. In addition, some incident eye diseases were analysed to be risk factors for SVI/B of incident glaucoma patients. These findings emphasised the importance of early detection of glaucoma onset, regular ophthalmological examinations to medicate higher IOP, and to prevent the progression to SVI/B. Also, the general importance of eye care management in addition to a solid working patient-doctor relationship will improve disease management. But prevention also depends on the early detection of non-ophthalmic conditions. Knowledge of the factors that may be responsible for increased risk of $\mathrm{SVI} / \mathrm{B}$ is important for all those involved in healthcare management to assess the need for medical care interventions and to further improve medical care.

Acknowledgements We are grateful to Christian Günster from the Scientific Research Institute of the AOK, WId0, for providing the data.

Contributors SN, DK and GD designed the model and the computational framework. GD supervised the work. SN performed the calculations and designed the figures and tables. SN and SF wrote the manuscript with input from all authors. RFG aided in interpreting the results. All authors discussed the results and contributed to the final manuscript. GD was responsible for the overall content as guarantor. GD accepted full responsibility for the finished work and/or the conduct of the study, had access to the data, and controlled the decision to publish.

Funding This work was supported by the Federal Ministry of Education and Research, Germany, Grant number 03ZZ0923A.

Competing interests None declared.

Patient and public involvement Patients and/or the public were not involved in the design, or conduct, or reporting, or dissemination plans of this research.

Patient consent for publication Not applicable.

Ethics approval This study does not involve human participants. A unique identification number anonymised each patient's data; hence, this study complied with the tenets of the Declaration of Helsinki and required no ethical approval.

Provenance and peer review Not commissioned; externally peer reviewed.

Data availability statement Data are available upon reasonable request.

Open access This is an open access article distributed in accordance with the Creative Commons Attribution Non Commercial (CC BY-NC 4.0) license, which permits others to distribute, remix, adapt, build upon this work non-commercially, and license their derivative works on different terms, provided the original work is properly cited, appropriate credit is given, any changes made indicated, and the use is non-commercial. See: http://creativecommons.org/licenses/by-nc/4.0/.

ORCID iD

Sophia Nestler http://orcid.org/0000-0001-5153-0202

\section{REFERENCES}

1 Quigley HA, Broman AT. The number of people with glaucoma worldwide in 2010 and 2020. Br J Ophthalmol 2006;90:262-7.

2 Kapetanakis VV, Chan MPY, Foster PJ, et al. Global variations and time trends in the prevalence of primary open angle glaucoma (POAG): a systematic review and meta-analysis. Br J Ophthalmol 2016;100:86-93.

3 Pascolini D, Mariotti SP. Global estimates of visual impairment: 2010. Br J Ophthalmol 2012;96:614-8.

4 Robert Koch-Institut Gesundheitsberichterstattung des Bundes. GBE-Themenheft. Blindheit und Sehbehinderung, 2017.
5 Finger RP, Fimmers R, Holz FG, et al. Incidence of blindness and severe visual impairment in Germany: projections for 2030. Invest Ophthalmol Vis Sci 2011;52:4381-9.

6 Bourne RRA, Jonas JB, Bron AM, et al. Prevalence and causes of vision loss in high-income countries and in eastern and central Europe in 2015: magnitude, temporal trends and projections. $\mathrm{Br} J$ Ophthalmol 2018;102:575-85.

7 Knauer C, Pfeiffer N. Erblindung in Deutschland - heute und 2030. Ophthalmologe 2006;103:735-41.

8 Finger RP, Bertram B, Wolfram C, et al. Blindness and visual impairment in Germany: a slight fall in prevalence. Dtsch Arztebl Int 2012:109:484-9.

9 Mauschitz MM, Li JQ, Larsen PP, et al. Epidemiologie hochgradiger Sehbehinderungen und Blindheit älterer Menschen in Deutschland. Ophthalmologe 2019;116:201-12.

10 Malihi M, Moura Filho ER, Hodge DO, et al. Long-term trends in glaucoma-related blindness in Olmsted County, Minnesota. Ophthalmology 2014;121:134-41.

11 Kotecha A, Fernandes S, Bunce C, et al. Avoidable sight loss from glaucoma: is it unavoidable? $\mathrm{Br} J$ Ophthalmo/ 2012;96:816-20.

12 Flaxman SR, Bourne RRA, Resnikoff S, et al. Global causes of blindness and distance vision impairment 1990-2020: a systematic review and meta-analysis. Lancet Glob Health 2017;5:e1221-34.

13 Claessen H, Kvitkina T, Narres M, et al. Markedly decreasing incidence of cause-specific blindness in Saxony (eastern Germany). Graefes Arch Clin Exp Ophthalmol 2021;259:1089-101.

14 Prokofyeva E, Zrenner E. Epidemiology of major eye diseases leading to blindness in Europe: a literature review. Ophthalmic Res 2012;47:171-88

15 Morris DS, Willis S, Minassian D, et al. The incidence of serious eye injury in Scotland: a prospective study. Eye 2014;28:34-40.

16 Shah A, Blackhall K, Ker K, et al. Educational interventions for the prevention of eye injuries. Cochrane Database Syst Rev 2009;4:CD006527.

17 Kreft D, Doblhammer G, Guthoff RF, et al. Incidence, individual, and macro level risk factors of severe binocular visual impairment and blindness in persons aged 50 and older. PLOS One 2021;16:e0251018.

18 Wolfram C, Pfeiffer N. Weißbuch Zur situation Der ophthalmologischen Versorgung in Deutschland. Deutsche Ophthalmologische Gesellschaft, München, 2012.

19 van Kleef R, McGuire TG, eds. Risk adjustment, risk sharing and premium regulation in health insurance markets: Theory and practice. London: Academic Press, 2018.

20 Chen PP. Blindness in patients with treated open-angle glaucoma. Ophthalmology 2003;110:726-33.

21 Yonekawa Y, Varma R, Choudhury F, et al. Risk factors for four-yea incident visual impairment and blindness: the Los Angeles Latino eye study. Ophthalmology 2011;118:1790-7.

22 Sinclair A, Hinds A, Sanders R. Ten years of glaucoma blindness in fife 1990-99 and the implications for ophthalmology, optometry and rehabilitation services. Ophthalmic Physiol Opt 2004;24:313-8.

23 O'Colmain U, Anijeet D, Vosoughi M, et al. Glaucoma blind registration in Fife (2000-2009) - a retrospective cohort study. Ophthalmic Physiol Opt 2011;31:360-6.

24 Mafwiri M, Bowman RJC, Wood M, et al. Primary open-angle glaucoma presentation at a tertiary unit in Africa: intraocular pressure levels and visual status. Ophthalmic Epidemiol 2005;12:299-302.

25 Gyasi M, Amoako W, Adjuik M. Presentation patterns of primary open angle glaucomas in North eastern Ghana. Ghana Med $J$ 2010;44:25-30.

26 Paula JS, Furtado JM, Santos AS, et al. Risk factors for blindness in patients with open-angle glaucoma followed-up for at least 15 years. Arq Bras Oftalmol 2012;75:243-6.

27 Blomdahl S, Calissendorff BM, Tengroth B, et al. Blindness in glaucoma patients. Acta Ophthalmol Scand 1997;75:589-91.

28 Eid TM, Spaeth GL, Bitterman A, et al. Rate and amount of visual loss in 102 patients with open-angle glaucoma followed up for at least 15 years. Ophthalmology 2003;110:900-7.

29 Lee PP, Feldman ZW, Ostermann J, et al. Longitudinal prevalence of major eye diseases. Arch Ophthalmol 2003;121:1303-10.

30 Luntz MH, Schenker HI. Retinal vascular accidents in glaucoma and ocular hypertension. Surv Ophthalmol 1980;25:163-7.

31 Kooner KS, AlBdoor M, Cho BJ, et al. Risk factors for progression to blindness in high tension primary open angle glaucoma: comparison of blind and nonblind subjects. Clin Ophthalmol 2008;2:757-62.

32 Gunnlaugsdottir E, Arnarsson A, Jonasson F. Five-year incidence of visual impairment and blindness in older Icelanders: the Reykjavik eye study. Acta Ophthalmol 2010;88:358-66. 
33 Dimitrov PN, Mukesh BN, McCarty CA, et al. Five-year incidence of bilateral cause-specific visual impairment in the Melbourne visual impairment project. Invest Ophthalmol Vis Sci 2003;44:5075-81.

34 Cedrone $\mathrm{C}$, Culasso $\mathrm{F}$, Cesareo $\mathrm{M}$, et al. Incidence of blindness and low vision in a sample population. Ophthalmology 2003;110:584-8.

$35 \mathrm{Kwon}$ YH, Kim CS, Zimmerman MB, et al. Rate of visual field loss and long-term visual outcome in primary open-angle glaucoma. Am $J$ Ophthalmol 2001;132:47-56.

36 Spry PGD, Sparrow JM, Diamond JP, et al. Risk factors for progressive visual field loss in primary open angle glaucoma. Eye 2005;19:643-51.

37 Kreft D, Doblhammer G, Guthoff RF, et al. Prevalence, incidence, and risk factors of primary open-angle glaucoma - a cohort study based on longitudinal data from a German public health insurance. BMC Public Health 2019;19:851.
38 Klein R, Klein BEK, Lee KE. Changes in visual acuity in a population. Ophthalmology 1996;103:1169-78.

39 Foran S, Mitchell P, Wang JJ. Five-year change in visual acuity and incidence of visual impairment: the blue Mountains eye study. Ophthalmology 2003;110:41-50.

40 Leske MC, Wu S-Y, Hyman L, et al. Four-year incidence of visual impairment: Barbados incidence study of eye diseases. Ophthalmology 2004;111:118-24.

41 Mbulaiteye SM, Reeves BC, Mulwanyi F, et al. Incidence of visual loss in rural Southwest Uganda. Br J Ophthalmol 2003;87:829-33.

42 Pollreisz A, Schmidt-Erfurth U. Diabetic cataract-pathogenesis, epidemiology and treatment. J Ophthalmol 2010;2010:608751

43 Riaz Y, Mehta JS, Wormald R. Surgical interventions for age-related cataract. Cochrane Database Syst Rev 2006;4:CD001323. 